\title{
Cure and Collapse Mechanism of Inorganic Mold Using Spherical Artificial Sand and Water Glass Binder*1
}

\author{
Katsunori Kosuge ${ }^{1, * 2}$, Motoo Sunaga ${ }^{2}$, Ryuhei Goda ${ }^{2}$, Hiroshi Onodera ${ }^{2}$ and Toshimitsu Okane ${ }^{1}$ \\ ${ }^{1}$ Advanced Manufacturing Research Institute, National Institute of Advanced Industrial Science and Technology, \\ Tsukuba 305-8564, Japan \\ ${ }^{2}$ Fuji Chemical Company, LTD., Nakatsugawa 509-9132, Japan
}

Artificial spherical sands were cured using water glass as a binder with or without addition of porous silica to prepare the test piece and aluminum alloy casting core. In order to clarify the curing and collapsibility mechanism of inorganic sand mold, the cross-linked structure between their particles were evaluated by SEM observation. A three-dimensional network of crosslinking bridges derived from water glass formed between the spherical particles enables the preparation of a core with sufficient strength for casting. The water glass added to cure the core requires less than $2 \mathrm{wt} \%$ by weight for the sand prepared by the melting method and about a third as much as that prepared by the sintering method. The high collapsibility of such an inorganic mold is due to the rapid elongation of crosslinking bridges between the particles when heated above a certain temperature so that the particles are separated from each other. Especially for spherical particles with a smooth surface, the relatively small amount of water glass for curing would cause collapsibility accelerated by the thinning of the crosslinked body wall occurring simultaneously with elongation. Furthermore, the addition of porous silica would induce elongation at a lower temperature as compared to when porous silica is not added, and is extremely effective for improving the collapsibility of the inorganic sand mold. [doi:10.2320/matertrans.F-M2018838]

(Received May 23, 2018; Accepted July 27, 2018; Published October 25, 2018)

Keywords: artificial sand, water glass, porous silica, inorganic sand mold, crosslinking bridge, collapsibility

\section{Introduction}

Sand mold casting is generally performed using an organic binder system because of considerations regarding production efficiency and workability. ${ }^{1,2)}$ However, atmospheric and work environment measures associated with the generation of harmful gases are big issues today. ${ }^{3,4)}$ It is widely known that inorganic sand mold casting is desirable from health and environmental viewpoints. Over the last few decades, an inorganic binder method based on water glass has been developed in the European automobile and casting industries $^{5-7)}$ and has been used in, for example, the production of engine parts. ${ }^{8)}$ Numerous patents relating to methods for manufacturing an inorganic mold containing water glass ${ }^{9,10)}$ have also been disclosed in Japan.

In contrast, along with environmental measures, the development of artificial sand has been advanced as an ideal foundry sand that meets the diverse needs of casting technology. ${ }^{2,11,12)}$ By using artificial sand, innovation in casting technologies such as high-precision casting, reduction of spent casting sand treated as waste, and improvement of productivity can be expected. Recently, examples of utilizing artificial sand are increasing, including the development of a 3D laminated sand molding technology. ${ }^{13)}$

However, there are still several issues that need to be addressed, such as the high raw-material cost of artificial sand and the low collapse property of inorganic sand molds. In addition, organic binders are currently in common use for sand molding of artificial sand. Although it is possible to apply the inorganic molding techniques disclosed in the patent to artificial sand, there have been few detailed reports.

\footnotetext{
${ }^{* 1}$ This Paper was Originally Published in Japanese in J. JFS 89 (2017) 470 476.

${ }^{* 2}$ Corresponding author, E-mail: k.kosuge@aist.go.jp
}

The authors have been continuously conducting research on the development of inorganic sand molding technologies using water glass as a binder and artificial sand as a foundry sand, and some research results of artificial sand including silica sand have been released. ${ }^{14,15)}$ In this study, scanning electron microscopy-energy dispersive X-ray spectroscopy (SEM-EDX) analysis of two artificial sand samples obtained by heating treatment of a test piece, and the casting test used as a core was performed. Here the curing and collapse mechanisms of inorganic sand molds using artificial sand are reported, which are clearer than those using silica sand.

\section{Experimental Procedure}

\subsection{Materials}

Artificial sand or silica sand was mixed with water glass having a $\mathrm{SiO}_{2} / \mathrm{Na}_{2} \mathrm{O}$ molar ratio of 2.1 and porous silica to prepare raw materials for sand casting. The chemical compositions of the foundry sands used, reproduced from the product catalog or published data, are shown in Table 1. Each artificial sand is graded by particle size, and Table 1 shows the grade numbers and the abbreviated notations used in this study. Two kinds of porous silica, spherical and irregular, were used, which are denoted by silica $A$ and silica $\mathrm{B}$ in the text, respectively. The specific surface area $\left(\mathrm{m}^{2} \mathrm{~g}^{-1}\right)$, pore volume $\left(\mathrm{mlg}^{-1}\right)$, and pore diameter $(\mathrm{nm})$ were 573 , 0.86 , and 6.2 for silica $A$ and were 530, 0.88, and 6.2 for silica B. These two kinds of silica have similar pore characteristics but with different particle size distributions, which were in the range from 75 to $500 \mu \mathrm{m}$ for silica A and from 150 to $250 \mu \mathrm{m}$ for silica B.

According to X-ray diffraction measurements, every artificial sand was found to be mainly composed of mullite $\left(3 \mathrm{Al}_{2} \mathrm{O}_{3} \cdot 2 \mathrm{SiO}_{2}\right)$. Among the fused artificial sand, coexistence of alumina was found in artificial sand L, but in artificial 
Table 1 Chemical compositions and abbreviated names of artificial and silica sands.

\begin{tabular}{|c|c|c|c|c|c|c|c|c|}
\hline \multirow{2}{*}{ Product name } & \multirow{2}{*}{$\begin{array}{c}\text { Abbreviated } \\
\text { Japanese } \\
\text { notation }\end{array}$} & \multirow{2}{*}{$\begin{array}{c}\text { Production } \\
\text { method }\end{array}$} & \multicolumn{4}{|c|}{ Chemical composition (\%) } & \multirow{2}{*}{$\begin{array}{l}\text { Product } \\
\text { grade used }\end{array}$} & \multirow{2}{*}{$\begin{array}{c}\text { Abbreviated } \\
\text { notation }\end{array}$} \\
\hline & & & $\mathrm{Al}_{2} \mathrm{O}_{3}$ & $\mathrm{SiO}_{2}$ & $\mathrm{Fe}_{2} \mathrm{O}_{3}$ & $\mathrm{TiO}_{2}$ & & \\
\hline Flattery sand & silica sand F & natural & 0.03 & 99.9 & 0.01 & 0.02 & & \\
\hline Lunamos & artificial sand $\mathrm{L}$ & melting & 63 & 32 & 1.3 & 2.5 & $\# 60, \# 110$ & $\mathrm{~L} 60, \mathrm{~L} 110$ \\
\hline Espearl & artificial sand $\mathrm{E}$ & melting & 72 & 20 & 2.8 & 3.31 & $\# 100$ & $\mathrm{E} 100$ \\
\hline AR sand & artificial sand $\mathrm{A}$ & melting & 78 & 15 & 2 & - & $\# 1500$ & A 1500 \\
\hline Naigai Cerabeads & artificial sand C & sintering & 61 & 36 & - & - & $\# 500$ & C500 \\
\hline
\end{tabular}

sands $\mathrm{A}$ and $\mathrm{E}$, multiple peaks other than mullite peaks could not be identified. Coexistence of alumina was also found in sintered artificial sand $\mathrm{C}$.

According to SEM observations, most particles of fused artificial sands L, A, and E were almost perfectly spherical with a smooth surface, on which small particles could be observed at $10,000 \times$ magnification. In contrast, the sintered artificial sand $\mathrm{C}$ had a non-uniform particle form with a somewhat low sphericity, exhibiting a clear concavo-convex pattern on the surface even at a few tens of magnification.

\subsection{Fabrication of sand molds and aluminum alloy casting tests}

Casting sand materials in an acrylic mold were tableted into $\varphi 50 \times 50 \mathrm{~mm}$ specimens using a sand rammer and then cured by a drying method in an oven at $120^{\circ} \mathrm{C}$ for $1-2 \mathrm{~h}$ or cured by a $\mathrm{CO}_{2}$ process. The compressive strength of the obtained cured test piece was measured.

In the casting test shown in Fig. 1(a), a core having external dimensions of $240 \mathrm{~mm} \times 60 \mathrm{~mm} \times 36 \mathrm{~mm}$ was used, and the main parts of the core were indicated by circled numbers (1) to (3) in Fig. 1(b). (1) is a thin connection part of a core and a baseboard to evaluate the core strength as a sand mold, and (2) and (3) have a pouch-like and a wavy structure, respectively, both of which corresponding core is generally known to be difficult to be collapsed.

Figure 2(a) shows a thin cylindrical casting with dimensions of $\varphi 200 \times 200 \mathrm{~mm}$ having a large hollow part with dimensions of $\varphi 146 \times 200 \mathrm{~mm}$ in the center as well as a narrow cavity $10 \mathrm{~mm}$. The cavity was sandwiched between two cylinders with thicknesses of $10 \mathrm{~mm}$ (outside) and $7 \mathrm{~mm}$ (inside). The core comprised three parts that were used in combination as shown in Fig. 2(b), i.e., a pair of arched molded bodies and a single cylindrical body, which gave the aforementioned narrow cavity and the central hollow part of the sand mold, respectively. In Fig. 2(b), the center core was made from a natural silica sand using a casting maker, and the arcuate cores surrounding the center core were made from artificial sand E. For each core, a wooden mold was filled with the foundry sand material by hand and cured by a drying method or a $\mathrm{CO}_{2}$ process in the same manner as that for the aforementioned test piece.

In the casting experiment, a greensand mold was mainly used as the master mold. The molten aluminum alloy JIS $\mathrm{AC} 2 \mathrm{~A}$ was poured into the mold at $720^{\circ} \mathrm{C}$ without applying any coating to the cores. After solidification, both the master mold and the baseboard parts were removed, and the casting

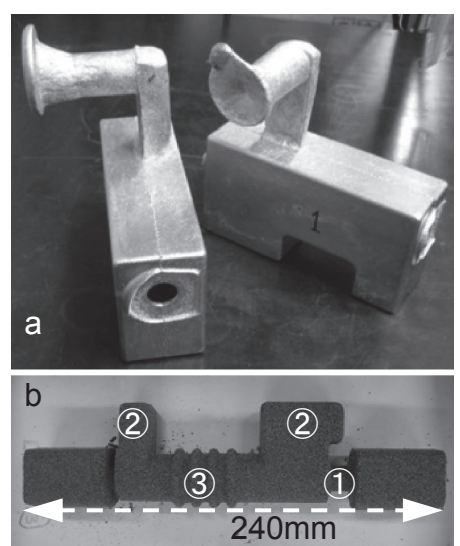

Fig. 1 Aluminum alloy casting (a) and its core (b).

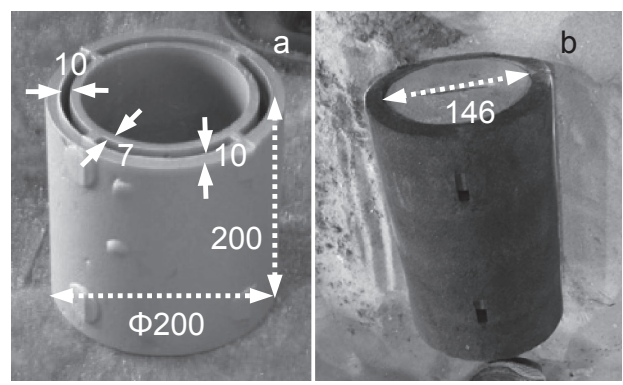

Fig. 2 Thin-walled cylindrical casting (a) and the cores comprising a pair of arch-shaped thin cores and a cylindrical core (b). The unit of length is millimeter.

was then tilted, shaken, and tableted to evaluate the collapse properties of the cores while recording a video. For the cast product in Fig. 1(a), after recovering core sands, the casting was divided into two parts, and the residual states of the core and the quality of casting surface were evaluated. Based on these experimental results, the collapsibility could be qualitatively classified into three types as follows: (1) most parts of the core can be recovered by merely tilting, (2) most parts of the core peeled off during mechanical vibration, and (3) the core was difficult to collapse even by mechanical vibration; these three types are denoted by $\odot, 0$, and $\times$, respectively, in this work.

\subsection{Analysis and evaluation methods}

The SEM-EDX analysis was mainly performed on artificial sand L and silica sand F. The particle surfaces and crosslinked structures were observed contained in the test 
Table 2 Preparation conditions of sand molds and compressive strength of test pieces and collapsibility of cores.

\begin{tabular}{|c|c|c|c|c|c|c|c|c|}
\hline $\begin{array}{l}\text { Sample } \\
\text { number }\end{array}$ & $\begin{array}{c}\text { Abbreviated } \\
\text { notation } \\
\text { in the text }\end{array}$ & $\begin{array}{c}\text { Type of } \\
\text { sand mold }\end{array}$ & $\begin{array}{l}\text { Curing } \\
\text { method }\end{array}$ & $\begin{array}{l}\text { Water } \\
\text { glass } \\
\text { (wt\%) } \\
\end{array}$ & $\begin{array}{l}\text { Porous } \\
\text { silica } \\
\text { (wt } \% \text { ) }\end{array}$ & $\begin{array}{c}\text { Initial } \\
\text { strength } \\
\text { (Mpa) }\end{array}$ & $\begin{array}{c}\text { Strength } \\
\text { heated at } \\
600^{\circ} \mathrm{C}(\mathrm{Mpa})\end{array}$ & $\begin{array}{c}\text { Collapsibilty } \\
\text { and Strength } \\
\text { reduction ratio (\%) }\end{array}$ \\
\hline $\mathrm{S} 1$ & L60 & test piece & drying & 1.4 & 0 & 7.31 & 0.44 & 94 \\
\hline \multirow{2}{*}{$\mathrm{S} 2$} & \multirow{2}{*}{ L110 } & core & drying & 2 & 1 & - & - & () \\
\hline & & main mold & drying & 1.4 & 0 & - & - & $\mathrm{x}$ \\
\hline S3 & L60 & test piece & drying & 1.4 & 0 & 3.48 & 0.88 & 75 \\
\hline $\mathrm{S} 4$ & L60 & test piece & drying & 1.4 & 0.73 & 2.52 & 0.75 & 70 \\
\hline $\mathrm{S} 5$ & L60 & test piece & $\mathrm{CO}_{2}$ & 1.4 & 0 & 2.09 & 0.75 & 64 \\
\hline S6 & silica sand $F$ & core & $\mathrm{CO}_{2}$ & 4 & 1 & - & - & 0 \\
\hline S7 & silica sand F & core & $\mathrm{CO}_{2}$ & 4 & 0 & - & - & $\mathrm{x}$ \\
\hline $\mathrm{S} 8$ & L60 & core & drying $/ \mathrm{CO}_{2}$ & $1 \sim 3$ & $0 \propto 1$ & - & - & ○ \\
\hline s9 & E100 & core & drying $/ \mathrm{CO}_{2}$ & 1.4 & $0 \sim 1$ & - & - & $\odot$ \\
\hline S10 & A 1500 & core & drying $/ \mathrm{CO}_{2}$ & 1.4 & $0 \sim 1$ & - & - & ( \\
\hline S11 & C500 & core & $\mathrm{CO}_{2}$ & 4 & 1 & - & - & ( \\
\hline $\mathrm{S} 12$ & C500 & Thin-walled core & $\mathrm{CO}_{2}$ & 4 & 1 & - & - & ( \\
\hline $\mathrm{S} 13$ & L110 & Thin-walled core & $\mathrm{CO}_{2}$ & 1.4 & 0 & - & - & $\mathrm{x}$ \\
\hline $\mathrm{S} 14$ & L110 & Thin-walled core & $\mathrm{CO}_{2}$ & 1.4 & 0.67 & - & - & $\odot$ \\
\hline
\end{tabular}

pieces heated at a predetermined temperature and in the cores for the casting test along with mapping evaluation of $\mathrm{Na}$, $\mathrm{Si}$ and $\mathrm{Al}$ elements. In this report, only the SEM images are shown, and the element distributions are described as changes in the behavior of crosslinking components (denoted by $\mathrm{Si}(\mathrm{Na})$ ) derived from water glass.

\section{Results and Discussions}

In order to clarify the curing and collapse mechanisms of the inorganic sand molds, test pieces and the cores were selected for SEM observation from among those fabricated under various conditions. The preparation conditions for these samples are shown at S1-S6 in Table 2. Furthermore, $\mathrm{S} 7-\mathrm{S} 14$ are listed in addition to S1-S6 in order to clarify the collapse behavior of the sand mold in more detail. In Table 2, the notations of test piece, core, and thin-walled core correspond to a molded body of dimensions $\varphi 50 \times 50 \mathrm{~mm}$ made by a sand rammer, the sand mold shown in Fig. 1(b), and the arcuate core in Fig. 2(b), respectively.

\subsection{Fundamental discussions of formation and trans- formation processes of crosslinked structure in test piece}

Figure 3 shows the morphological and structural changes of crosslinked bridges formed in the gap and surface of particles, for the test piece S1 sown in Table 2 in the case of heating at $120^{\circ} \mathrm{C}$ and $600^{\circ} \mathrm{C}$. Changes in "structure crosslinking between particles (crosslinked bridges)" from a to $\mathrm{c}$ in Fig. 3 show that the crosslinking component $\mathrm{Si}(\mathrm{Na})$ grows so as to spread between the particles by increasing the heating temperature. In addition, the ring-shaped raised portions in Figs. 3(b) and 3(d) correspond to the state in which the crosslinked body is sliced in a circular shape (hereinafter referred to as trace structure). It would be a trace of a crosslinked body formed by peeling after contact with
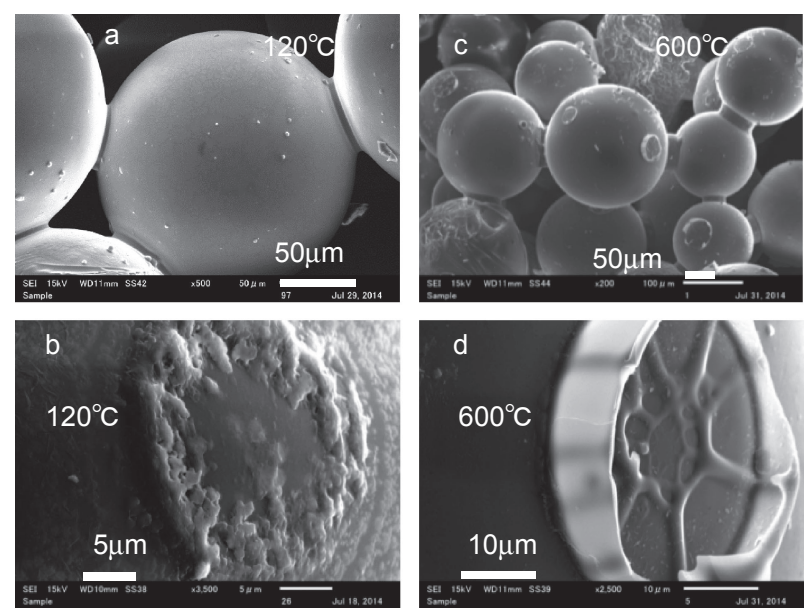

Fig. 3 Morphological transformation observed in S1 of crosslinked network structure (a) to (c) and of crosslinked trace structure (b) to (d) heated at $120^{\circ} \mathrm{C}(\mathrm{a}),(\mathrm{c})$ and $600^{\circ} \mathrm{C}(\mathrm{b}),(\mathrm{d})$.

another particle. The remarkable change in the trace structure due to heating temperature is evident. A remarkable change in the trace structure by increasing the heating temperature is evident. It can be observed that the crosslinked body transforms from a smooth structure in the unheated state (Fig. 4(a)) to an agglomerated structure among small particles due to dehydration caused by heating (Fig. 4(b)). Then, through smoothing due to fusion between these small particles by condensation on heating (Fig. 4(c)), the crosslinked body is found to eventually homogenize over $400^{\circ} \mathrm{C}$ (Figs. 4(d) and 4(e)). The thermal change in this crosslinked structure reflects clearly in the length of the crosslinked body between the particles indicated by the arrow in the Figure. The inter-particle distance gradually expands from the unheated state to $300^{\circ} \mathrm{C}$ followed by a remarkably rapid enlargement at $400^{\circ} \mathrm{C}$. This distance hardly changes when further increasing the temperature, so it might be concluded 


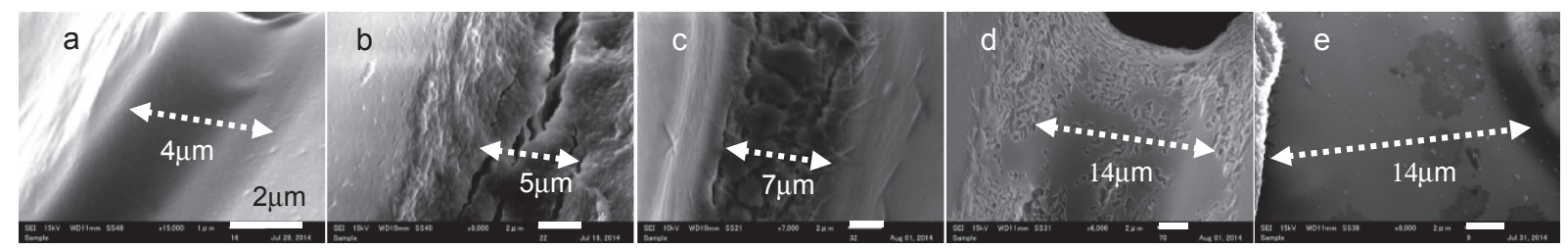

Fig. 4 Changes in length and morphology of crosslinking bridges for $\mathrm{S} 1$ with increasing temperature: (a) unheated, (b) $120^{\circ} \mathrm{C},(\mathrm{c}) 300^{\circ} \mathrm{C}$, (d) $400^{\circ} \mathrm{C}$, and (e) $600^{\circ} \mathrm{C}$. The scale bars are all $2 \mu \mathrm{m}$.
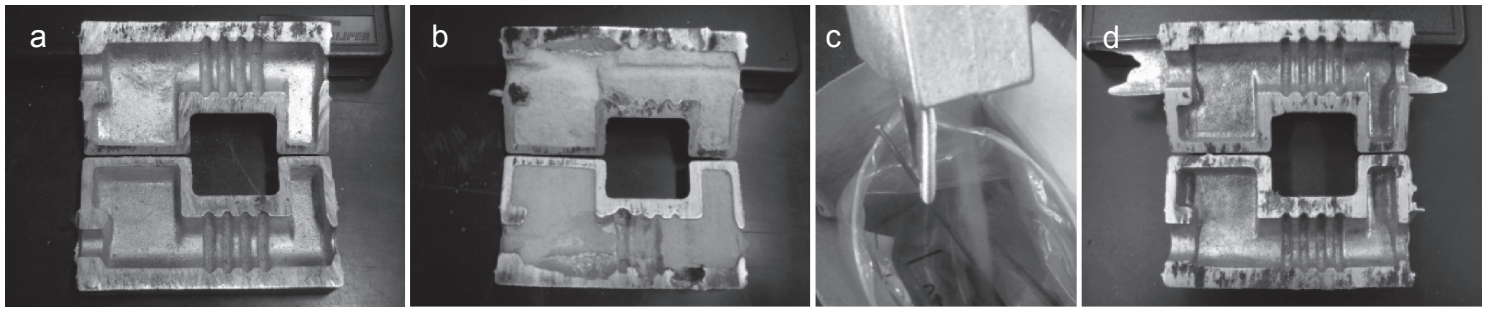

Fig. 5 Two-piece casting showing significant differences in the collapse of the core with (a) and without (b) addition of porous silica A for S6 and S7, respectively. (c) Collapse behavior of the L110 core for S2 due to just tilting of the casting, and (d) Two-piece casting after collapse showing that residual sand is hardly observed.

that the inter-particle distance is maintained at first glance at least above $400^{\circ} \mathrm{C}$.

In addition, the SEM observation results of changes in the crosslinked structure with increasing temperature correspond well with changes in the element distribution. In a hypothetical state in which particles do not interfere with each other, the crosslinking component $\mathrm{Si}(\mathrm{Na})$ widely covers particles and uniformly distributes over their surfaces. However, $\mathrm{Si}(\mathrm{Na})$ concentrates around the mutual interference region as a crosslinking precursor formed by contact and collision between particles, while the $\mathrm{Si}(\mathrm{Na})$ content decreases in the vicinity of that region. As a result, heterogeneity occurs in the $\mathrm{Si}(\mathrm{Na})$ concentration distribution on the particle surface. From the unheated state to around $300^{\circ} \mathrm{C}$, the form of crosslinked bridges resembles that at $120^{\circ} \mathrm{C}$ at first glance, during which the crosslinking component $\mathrm{Si}(\mathrm{Na})$ exists like a paste joining the particles. Consequently, as shown in Fig. 3(b), the trace structure of $\mathrm{Si}(\mathrm{Na})$ has a thin and uneven convex-concave form. As the paste is drying due to temperature rise, the trace structure of $\mathrm{Si}(\mathrm{Na})$ becomes clearly visible on the particle surface as shown in Fig. 3(c). At $600^{\circ} \mathrm{C}$, pasty $\mathrm{Si}(\mathrm{Na})$ spread on the particle surface agglomerates and then elongates into a thin homogeneous wall of the crosslinked layer due to a change considered to be crystal growth, as shown in Fig. 3(d), which separates the particles from each other.

\subsection{Crosslinking structures of core and main mold recovered after casting test}

First, regarding two silica sands of S6 and S7 listed in Table 2 used as a comparative sample against artificial sand, images of divided castings obtained with and without adding silica A are shown in Figs. 5(a) and 5(b), respectively. In the case with the addition of silica A, by tableting the casting with a plastic hammer, some parts of the core peeled off and almost all of the remaining core could be further recovered by mechanical vibration. Figure 5(a) showing two divisions of the casting indicates that residual sand is hardly observed even in the bag-like and corrugated portions, and the casting surface is also of good quality. In contrast, in the case with no addition of silica $A$, even by mechanically vibrating the casting, almost all of the core remained inside the casting (Fig. 5(b)) because of its strong hardened state and furthermore casting failure due to gas defect is evident.

For S2 using the same artificial sand L110 for the main mold and the core as shown in Table 2, a large quantity of the core dropped simply by tilting it after casting as shown in Fig. 5(c), and almost all of the remaining core could be recovered by simple tableting. Figure 5(d) shows that little residual core is observed except for sand which thinly adhered on the casting surface. In contrast, the main mold was an extremely hard body, and even if it was strongly tableted with a hammer, it could not easily be collapsed.

SEM images of the collapsed core of S6 using silica sand listed in Table 2 are shown in Figs. 6(a) and 6(b). The crosslinked body and the trace structure of the inter-particle in the silica sand are non-uniform due to the aggregation of irregularly shaped particles. Details concerning the relationship between the crosslinked structure and the curing and collapse mechanisms for silica sand compared with artificial sand are described in Section 3.3. In contrast, SEM images of the collapsed core and main mold using artificial sand are shown in Figs. 6(c), 6(d), and 7, respectively. The morphologies of the crosslinked body and trace structure are similar to those of the structures heated at $600^{\circ} \mathrm{C}$ in the basic test using a test piece, as shown in Figs. 3(c) and $3(\mathrm{~d})$, respectively. Therefore, it is obvious that elongation of the crosslinked body occurred after pouring the molten aluminum alloy.

In contrast, as shown in Fig. 7(a), the expansion between particles in the main mold and the trace structure are not clear. However, when compared with Fig. 3(b) for the case at $120^{\circ} \mathrm{C}$, it is recognized that the swelling of the trace structure of the main mold is larger as shown in Fig. 7(b), so the change of such a crosslinked structure would be in a thermally more advanced state. Furthermore, considering that 

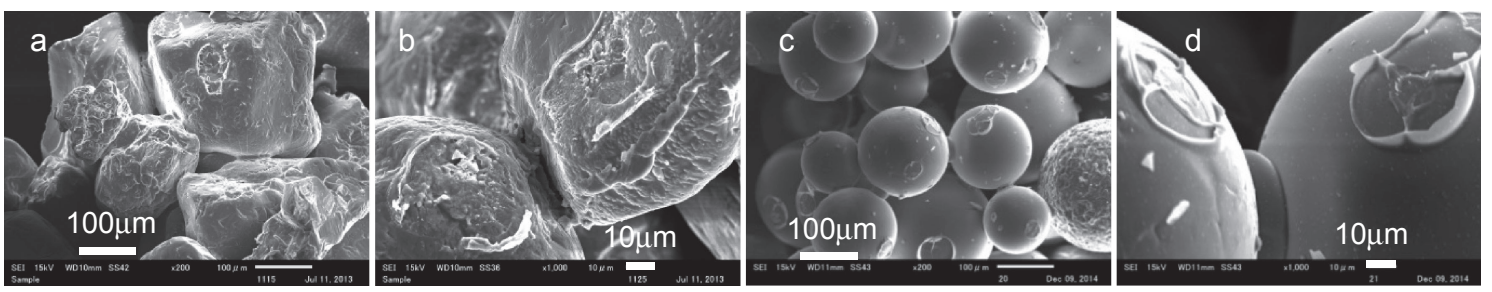

Fig. 6 Morphology of disintegrated core recovered after casting: (a), (b) for S7 and (c), (d) for S2, which used silica sand F and artificial sand L110 as the core sand, respectively.
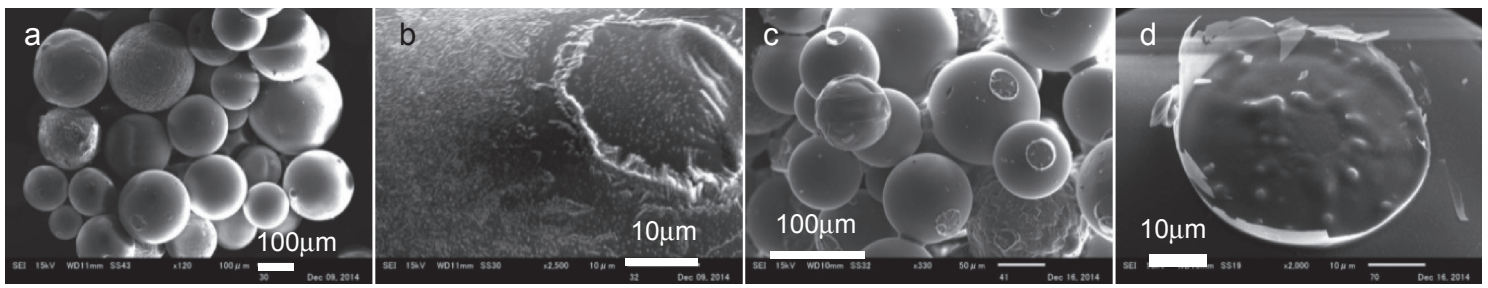

Fig. 7 Morphology of the main mold recovered after casting: (a), (b) for S2 and (c), (d) for its heated product at $600^{\circ} \mathrm{C}$.

the main mold is difficult to collapse, the crosslinked body is thought to be in a state as shown in Fig. 4(c), which tends to spread like a paste on the particle surface rather than extend the distance between the particles. Therefore, it can be regarded as a structure with high crosslinking strength between particles. It is noted that when part of the main mold was heated in an electric furnace at $600^{\circ} \mathrm{C}$ for $10 \mathrm{~min}$, changes in the crosslinked structure were observed as can be seen in Figs. 7(c) and 7(d), e.g., elongation of the interparticle crosslinked body, actualization of the trace structure, and thinning of the crosslinked wall. In addition, the heated mold can easily be crushed with the fingertips, strongly supporting the notion that high collapsibility is induced by elongation of the crosslinked body.

\subsection{Curing and collapse mechanisms of inorganic molds}

The changes in the crosslinked structure and collapse behavior of various sand molds, such as core, master mold after the casting test, and test piece after the heat treatment were investigated based on the SEM-EDX analysis. As the result, the estimated mechanism of the curing and collapse of the inorganic molds is shown in Fig. 8.

Artificial sand particles form a three-dimensional network crosslinked by water glass components $(\mathrm{Si}(\mathrm{Na}))$ and are cured as shown in Fig. 8(a). And strong test pieces and cores are molded. As the heating temperature increases, the crosslinked body represented by the black squares in Fig. 8(b) elongates, leading to expansion of the spaces between the particles (white arrow). As a result, the reverse force works in whole sand mold, so as to maintain the fixed shape (black arrow), the bond between the particles becomes brittle and the crosslinked bodies break down one after another, and finally the sand mold collapses as shown in Fig. 8(c).

As indicated in Table 2 for S2, S8, and S10, the curing and collapse mechanisms of the crosslinked structure in Fig. 8 were commonly found in fused spherical artificial sands with smooth surface particles. For sintered artificial sand $\mathrm{C}$ having a rough surface (S11 in Table 2), the amount of water glass
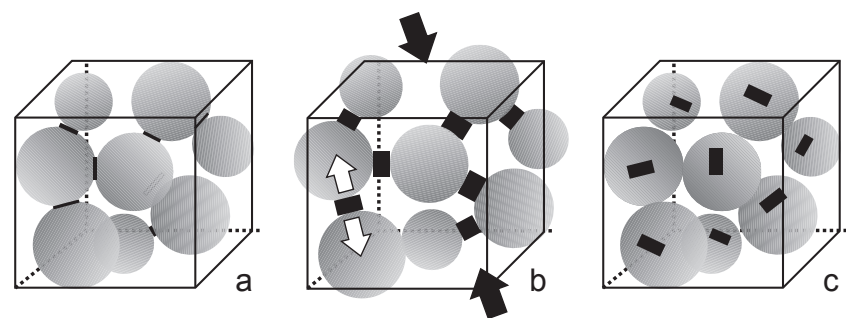

Fig. 8 Schematic drawings of a three-dimensional cured spherical particle network formed by crosslinking bridges (a), expansion of inter-particle spacing due to elongation of crosslinked bridges by heating (b), and the resulting collapse of crosslinked particles (c). See the main text for a description of the black squares and the two types of arrows.

added for curing was approximately 4.0 mass $\%$, which is approximately 3 times higher than that required to cure fused sand $(1.4$ mass $\%)$. In contrast, regardless of the manufacturing method of artificial sands, the collapse phenomenon illustrated in Fig. 8(d) was commonly observed in the casting core of Fig. 1.

In addition, the sand mold using silica sand $F$ could be cured with 4 mass $\%$ water glass, which is the same amount as artificial sand C. However, remarkable differences in the crosslinked structure were observed between them. As shown in Figs. 6(a) and 6(b), for silica sand F, a non-uniform structure is formed, which is recognized as an aggregated particle group rather than a crosslinked network structure. In more detailed observations, the silica sand composed of irregularly shaped particles with various sizes and surface morphologies; therefore, the particles are bridged via contact surfaces of various shapes and sizes, and the length of the crosslinked body is non-uniform. It is considered that such a crosslinked structure can bond particles relatively strongly because of a large contact area. Therefore, it is presumed that the susceptibility to force-induced collapsibility for the silica sand mold would be reduced compared with that for the artificial sand mold comprising spherical particles.

Furthermore, the addition of silica accelerates the collapse of the core, not only for the silica sand S6 shown in Fig. 5(a) 
and (b) but also for the artificial sand. In the case of the cast product in Fig. 1 for fused artificial sands S8 to S10 listed in Table 2, the curing and collapse mechanisms shown in Fig. 8 can be applied regardless of the addition of porous silica, although such addition was indispensable for inducing high collapse performance on the sintered sand C. However, in the case of the thin-walled core in Fig. 2, every artificial sand mold of L, E, and A as well as C could not be collapsed by mechanical vibration after casting. It can be seen in Figs. 5(a) and 5(b) that the addition of porous silica causes very significant collapse phenomena in such casting molds. Further, as an example, for S12 and S14 using C500 and L110 as shown in Table 2, the high collapsibility was imparted to the thin-walled core by addition of silica $A$ and silica $B$, respectively. It was recognized that the type of porous silica affected the curing condition of the inorganic sand mold, however have no influence on the collapse properties of such cured body.

In order to examine the effect of porous silica addition on the collapse property of inorganic sand molds, SEM observations of S3, S4, and S5 using artificial sand L60 were carried out, in which a homogeneous crosslinked network was formed. According to the comparison of crosslinked structures in Fig. 9, it is clear that the distance between particles becomes longer with the addition of porous silica (c, d) than that without (a, b). Expansion of the space between particles is also observed in the sand mold cured by a $\mathrm{CO}_{2}$ process, as shown in Figs. 9(e) and 9(f). According to a more detailed SEM observation in Fig. 9(b), in addition to the existence of many small particles on the crosslinked bridge and its periphery, these particles are agglomerated and fused, which may indicate a transitional process in the

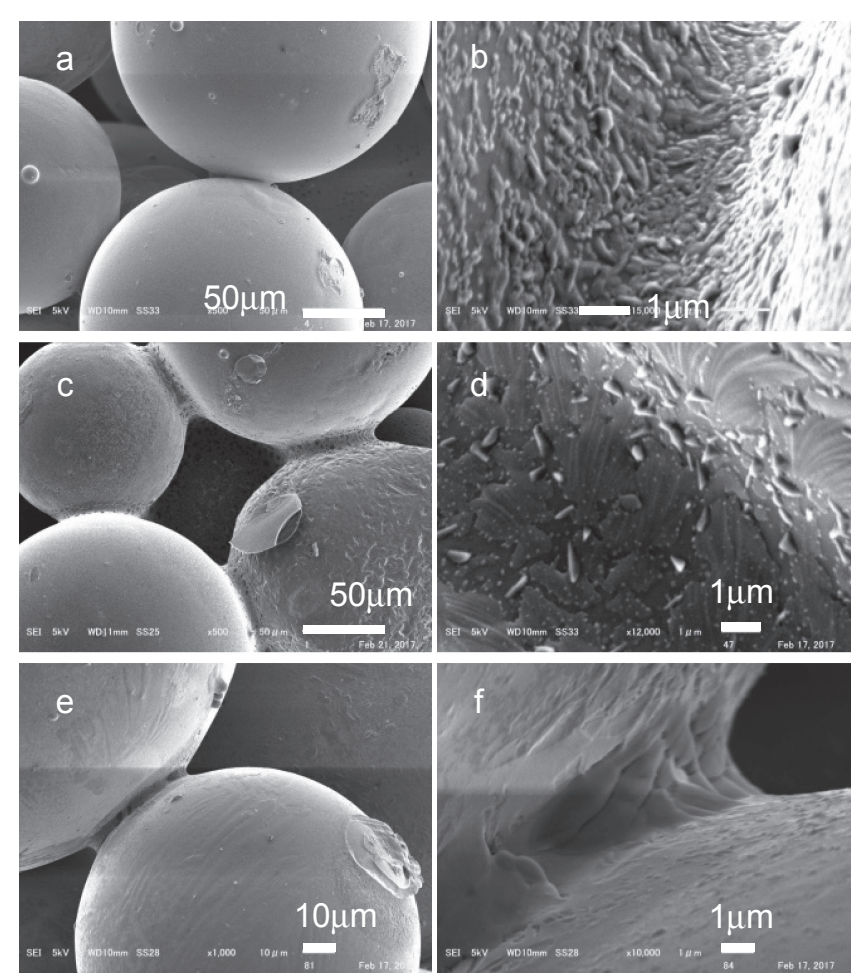

Fig. 9 Morphological changes in the crosslinked structure due to differences in the curing method: (a), (b) for S3, (c), (d) for S4, and (e), (f) for S5. smoothing of the crosslinked body. In contrast, it should be noted that the addition of porous silica would promote smoothing of the crosslinked body by fusing small regions so as to take in a small number of elongated particles as shown in Fig. 9(d). Therefore, it is reasonable to assume that the addition of porous silica causes the crosslinked body to extend as shown in Fig. 9(c) even at $120^{\circ} \mathrm{C}$, and collapsibility expresses in a lower heating state than that without addition.

The structural change of the crosslinked bodies can be explained based on Iler's comprehensive research. ${ }^{16)}$ Generally, dissolved silica species in water glass aqueous solution grow into high molecular weight colloidal particles through repeated dehydration condensation. These particles being dispersed in a solution are called primary particles or silica sol. The silica sol changes in the following two different polymerization processes depending on the $\mathrm{pH}$ and the existence of salts: (1) primary particles grow to a certain size and become stable colloidal silica, or (2) primary particles grown to a certain size contact each other by chemical bonding and are eventually gelled through the formation of a three-dimensional network.

In our system, the silica sol derived from water glass would be transformed into a gel by a polymerization process under aggressive external adjustments, such as drying/ heating, $\mathrm{CO}_{2}$ gas treatment, and the addition of porous materials, resulting in different crosslinking structures between particles through various sol-gel transformation processes.

The added porous silica would promote stabilization and growth of the silica sol while increasing the alkalinity of the water glass by adsorption of water molecules. Under the same drying condition, larger grown sols combine and gel than the case of Fig. 9(b) with no addition of the porous silica. As a result, it is seemed that a smooth and bulky crosslinked structure is formed as shown in Fig. 9(d). In contrast, with $\mathrm{CO}_{2}$ gas process, since the alkalinity of the sol solution decreases, relatively small primary particles cause the formation of a three-dimensional network structure followed by gelation. As a result, it is considered that a more homogeneous crosslinked structure tends to form to facilitate the extension of inter-particle spacings, as shown in Fig. 9(f).

\section{Conclusion}

In the foundry industry, efforts to reduce health and environmental burdens have become important, and the conversion of organic binders, which are a cause of harmful gas generation, to water glass and the development of related technologies have attracted a great deal of attention.

In this study, heating experiments using a cylindrical test piece and an aluminum alloy casting test with a core filled in wooden mold were conducted using water glass as a binder for artificial sand. The crosslinked body formed between the sand particles and the trace structure formed on the particle surfaces were evaluated by SEM observations, and the curing/collapse mechanisms of inorganic sand molds were investigated based on the changes in the crosslinked structure. 
Artificial sand comprising spherical particles having a smooth surface cures as a sand mold by forming a threedimensional network of homogeneously crosslinked bodies with the addition of a relatively small amount of water glass. The facile collapsibility of the inorganic sand mold was found to be due to the stretching of the crosslinked body, namely increasing distances between the spherical particles with increasing heating temperature. In particular, with smooth spherical particles, it is possible to reduce the amount of water glass required for curing, and the collapsibility is promoted by thinning of the crosslinked layer occurring simultaneously with elongation.

The addition of porous silica causes elongation of the crosslinked body at a lower temperature than without addition and is extremely effective at improving the collapse properties of the inorganic sand mold. The addition of porous silica has great potential for the development of sand casting technologies for thin castings having large volume cavities with a relatively narrow and long shape.

Almost no practical examples of inorganic molding technology based on a combination of artificial sand and water glass have been reported. These research results are expected to contribute to the development of future inorganic sand casting technologies from the viewpoints of environmental measures, improvement of productivity, and the depletion of high-quality natural casting sand.

\section{Acknowledgments}

The authors would like to thank President Ichiro Nakajima and Mr. Sakamoto of Nakajima Alloy Co., Ltd. and
President Satoru Okamoto of Izumu East Co., Ltd. for their considerable technical support with the aluminum alloy casting test as well as their valuable comments on the casting results. This work was supported by the Small and Medium Enterprise Agency (SME) both by a grant-in-aid from the Strategic Core Technology Advancement Program (Supporting Industry Program) and also from the Innovative Manufacturing, Commercial and Service Development Program.

\section{REFERENCES}

1) N. Kayama: Introduction to Casting (in Jpn. Imono no Ohanashi), (Japan Standard Association, 1992) Chapter 3.

2) Y. Nagai: J. JFES 82 (2010) 753-757.

3) H. Miyake: J. JFES 72 (2000) 549-558.

4) S. Izui: J. JFES 79 (2007) 419-425.

5) H. Polzin: Inorganic Binders for Mould and Core Production in the Foundry, (Berlin Schiele \& Schön, 2014).

6) F. Czerwinski, M. Mir and W. Kasprzak: Int. J. Cast. Met. Res. 28 (2015) 129-139.

7) L. Zaretskiy: Int. J. MetalCast. 10 (2016) 88-99.

8) J. Müller: Translation from GIESSEREI 99 (2012) 52-58.

9) Japan patent JP2013-111602A.

10) Japan patent JP2014-117740A

11) T. Konno: Sokeizai 49 (2008) 30-35.

12) Y. Kurokawa and Y. Amahisa: Sokeizai 49 (2008) 36-40.

13) Y. Fukuda and Y. Tomita: J. Soc. Insturum. Control Eng. 54 (2015) $412-415$.

14) K. Kosuge, M. Sunaga, R. Gouda, H. Onodera, K. Yokoi and T. Okane: Reports of the 167th JFS Meeting, (2015) p. 52.

15) K. Kosuge, M. Sunaga, R. Gouda, H. Onodera and T. Okane: Reports of the 167th JFS Meeting, (2015) p. 53.

16) R.K. Iler: The Chemistry of Silica, (John WILEY \& Sons, 1979) pp. 172-311. 